WSRC-TR-2002-00365

\title{
Solvent Quality Testing
}

Mark L. Crowder and Major C. Thompson

August 2002 
This document was prepared in conjunction with work accomplished under Contract No. DE-AC09-96SR18500 with the U. S. Department of Energy.

\section{DISCLAIMER}

This report was prepared as an account of work sponsored by an agency of the United States Government. Neither the United States Government nor any agency thereof, nor any of their employees, makes any warranty, express or implied, or assumes any legal liability or responsibility for the accuracy, completeness, or usefulness of any information, apparatus, product or process disclosed, or represents that its use would not infringe privately owned rights. Reference herein to any specific commercial product, process or service by trade name, trademark, manufacturer, or otherwise does not necessarily constitute or imply its endorsement, recommendation, or favoring by the United States Government or any agency thereof. The views and opinions of authors expressed herein do not necessarily state or reflect those of the United States Government or any agency thereof.

This report has been reproduced directly from the best available copy.

Available for sale to the public, in paper, from: U.S. Department of Commerce, National Technical Information Service, 5285 Port Royal Road, Springfield, VA 22161, phone: (800) 553-6847, fax: (703) 605-6900

email: orders@ntis.fedworld.gov

online ordering: http://www.ntis.gov/help/index.asp

Available electronically at http://www.osti.gov/bridge

Available for a processing fee to U.S. Department of Energy and its contractors, in paper, from: U.S. Department of Energy, Office of Scientific and Technical Information, P.O. Box 62, Oak Ridge, TN 37831-0062,

phone: (865)576-8401,

fax: (865)576-5728

email: $\underline{\text { reports@ adonis.osti.gov }}$ 
WSRC-TR-2002-00365

\section{Solvent Quality Testing}

\section{Mark L. Crowder and Major C. Thompson}

August 2002

\section{APPROVALS:}

Mark L. Crowder, Author

Date

Actinide Technology Section

Major C. Thompson, Author

Date

Actinide Technology Section

John H. Gray, Technical Reviewer

Date

Actinide Technology Section

Alice M. Murray, Manager

Date

Actinide Laboratory Programs 
WSRC-TR-2002-00365

\section{Summary}

Solvent from H Canyon's $2^{\text {nd }}$ Uranium Cycle (Tank 902) was received in June 2001. Based on chemical analyses, extraction performance, and phase separation behavior, the solvent was of very good quality and was not a cause of product contamination problems.

\section{Introduction}

The Savannah River Site (SRS) is working to purify highly enriched uranium (HEU) to be blended with natural uranium for eventual use as fuel in Tennessee Valley Authority (TVA) reactors. The HEU materials in this campaign are typically $60-70 \%$ enriched in uranium-235, and will be blended down to $4.95 \%$. Since the blended product must meet strict purity specifications, the HEU will be purified by solvent extraction in the $1^{\text {st }}$ and $2^{\text {nd }}$ Uranium Cycles of H Canyon. These cycles are part of the "HM Process".

Since the 1970's, the HM Process has used 7.5 vol\% tri-n-butyl phosphate (TBP) in a diluent as the solvent. (The current diluent, $n$-paraffin, is a mixture of straight-chain hydrocarbons from C-12 to C-16.) The solvent extracts uranium from high acid solutions, leaving other contaminants in the aqueous solution. Uranium is stripped from the solvent by dilute acid, resulting in a pure aqueous product stream. The solvent is reused after washing with sodium carbonate and dilute nitric acid solutions.

In the $2^{\text {nd }}$ Uranium Cycle, ferrous sulfamate is added to provide plutonium decontamination. Throughout 2001, H Canyon observed iron and sulfur contamination in the uranium product solution from $2^{\text {nd }}$ Uranium Cycle. This product stream, called 1EU, contains about $6 \mathrm{~g} / \mathrm{L}$ of highly enriched uranium. In addition, neptunium levels in $1 \mathrm{EU}$ were above the specification limit. This study was conducted to determine if solvent quality was causing these problems. Later, the source of the iron and sulfur contamination was identified as something other than the solvent. ${ }^{1}$ Nevertheless, the following report is useful for understanding solvent quality testing.

Typical plant solvent from H Canyon Tank 902 (used in $2^{\text {nd }}$ Uranium Cycle) was obtained in early June 2001. To evaluate the solvent's quality, a wide range of tests was performed. This report covers analytical results, phase separation behavior, and extraction testing. Whenever possible, performance of plant solvent was compared to that of new solvent.

\section{Analytical Results}

A range of analytical tests indicated that the Tank 902 solvent was in very good condition. $^{2}$

\footnotetext{
${ }^{1}$ Frushour, R.A., "Engineering Path Forward PF-HCAN-02-0067: Iron \& Sulfur Carryover in $2^{\text {nd }} \mathrm{U}$ Cycle", Feb. 22, 2002.

${ }^{2}$ Recorded in Laboratory Notebook WSRC-NB-99-00096, M.L. Crowder.
} 
1. Samples tested for alpha and beta activity showed $<6$ and $150 \mathrm{dpm} / \mathrm{mL}$, respectively. These low values indicate the solvent wash is very effective.

2. Gamma emitters had less than detectable activity.

3. Based on ion chromatography, dibutylphosphoric acid (DBP) was $<10 \mathrm{ppm}$, which is very good. ${ }^{3}$ DBP is a well-known degradation product that hinders solvent performance.

4. The Tank 902 samples had no visible solids. A $250-\mathrm{mL}$ sample was filtered and the filter paper was viewed by a Scanning Electron Microscope (SEM). Some solids were found in the 20-40 micron range. Qualitative analysis of these solids was inconclusive: the solids may have contained aluminum and silicon, with smaller amounts of iron, or they may have been organic, which cannot be detected with this instrument.

5. To get a better indication of solids content, a 200-mL sample of Tank 902 solvent was filtered and the $0.45-\mu \mathrm{m}$ filter paper was dissolved in $8 \mathrm{M}$ nitric acid. Unused filter paper was also dissolved in $8 \mathrm{M}$ acid as a blank. Samples of these solutions were analyzed for elemental content by ICP-ES (Inductively coupled plasma-emission spectroscopy). The concentration of Fe, $\mathrm{S}$ and most other elements were essentially the same for the filtered Tank 902 sample and the blank. Only phosphorous (P) was more prevalent in the Tank 902 sample, presumably due to liquid holdup in the filter paper. Hence, no solids were found in the solvent.

6. Organic analyses indicated that neither Tank 902 solvent nor the fresh, clean solvent had volatile organic compounds (e.g., butanol) above $0.01 \%$. A study of semivolatile organic compounds showed one difference between the two solvents. Tank 902 solvent contained about $10-20 \%$ branched hydrocarbons, presumably caused by degradation of n-paraffin. As expected, the fresh, clean solvent contained only straight-chain hydrocarbons. As noted below, this difference did not affect extraction performance. Within analytical variation, the TBP content was the same for both solvents.

The results of various analytical tests indicated that the Tank 902 solvent was in very good condition. The solvent was also tested for extraction performance and phase separation.

\section{Extraction Performance}

Batch extraction tests were performed to compare Tank 902 solvent to new solvent. Depleted uranium (DU) was dissolved in $4.3 \mathrm{M} \mathrm{HNO}_{3}$ to simulate $2^{\text {nd }}$ Uranium Cycle feed. This feed was extracted into each solvent, and samples were taken before and after extraction. The resulting solvent was stripped with $0.01 \mathrm{M} \mathrm{HNO}_{3}$ three separate times. In all cases aqueous and organic volumes were $5 \mathrm{~mL}$. Samples of the aqueous solutions were analyzed for U content by ICP-MS (Inductively coupled plasma-mass spectroscopy). The results, shown in Table 1, indicate that the extraction and stripping behavior of the two solvent types was essentially the same.

\footnotetext{
${ }^{3}$ Rief, D.J., and J.H. Gray, Good Solvent Criteria, WSRC-RP-91-477, April 26, 1991.
} 
WSRC-TR-2002-00365

Table 1. Batch Extraction Results

\begin{tabular}{|l|c|c|c|c|c|}
\hline \multirow{2}{*}{ Solvent Used } & \multicolumn{5}{|c|}{ Depleted Uranium, g/L } \\
\cline { 2 - 6 } & Feed & Extracted Feed & $1^{\text {st }}$ Strip & $2^{\text {nd }}$ Strip & $3^{\text {rd }}$ Strip \\
\hline Tank 902 & \multirow{2}{*}{$6.4^{*}$} & 1.3 & 5.1 & 0.51 & 0.003 \\
\cline { 1 - 5 } New solvent & & 1.2 & 4.9 & 0.31 & 0.003 \\
\hline
\end{tabular}

*An average of results from both ICP-MS and U-Chemchek. All others by ICP-MS.

In addition, three miniature mixer-settlers tests were conducted to compare larger-scale extraction and stripping behavior of the two solvent types. (A more detailed description of this test method is provided separately ${ }^{4}$ ). Two runs were done with Tank 902 solvent from $\mathrm{H}$ Canyon, and one run was done with new 7.5\% TBP. For the three runs, all flow rates and stream concentrations were the same. Two banks (16 stages each) of miniature mixer-settlers, or mini-banks, were operated, simulating the 2nd U Cycle. Depleted uranium (@ $5.5 \mathrm{~g} / \mathrm{L}$ in the feed) was used instead of HEU, and typical plant levels of neptunium, plutonium, iron, and sulfur were added to the feed.

Mini-bank test results are shown in Table 2. In all three runs, uranium extraction was sufficient, with product solutions having more than $7 \mathrm{~g} \mathrm{U} / \mathrm{L}$. Also, as shown in Table 2, the rejection of plutonium and neptunium into the waste stream was satisfactory for both solvent types. In addition, the mass balances for plutonium and neptunium closed to within $10 \%$.

Table 2. Solvent Performance in Mini-banks. (Basis $=1 \mathrm{~mL}$ Feed)

\begin{tabular}{|l|l|c|c|}
\hline Solvent Type & \multicolumn{1}{|c|}{ Stream } & Pu, dpm & Np, dpm \\
\hline & Feed (1DF) & 14400 & 4060 \\
\hline \multirow{2}{*}{$\begin{array}{l}\text { Tank 902 } \\
\text { (Avg. of 2 runs) }\end{array}$} & Waste (1DW) & 14400 & 3740 \\
\cline { 2 - 4 } & Product (1EU) & $<5^{*}$ & $<20^{*}$ \\
\hline \multirow{2}{*}{ New } & Waste (1DW) & 13800 & 4150 \\
\cline { 2 - 4 } & Product (1EU) & $<30^{*}$ & $2^{*}$ \\
\hline
\end{tabular}

* For reference, $20 \mathrm{dpm} / \mathrm{mL}$ Feed is equal to 48 Bq/g U Product (@ $7 \mathrm{~g}$ U/L Product)

\section{Disengagement Time}

Disengagement time is the time required for organic and aqueous phases to separate after vigorous mixing. Visual determination of the exact time of separation is difficult. Nevertheless, solvent samples of $4 \mathrm{~mL}$ were placed in centrifuge tubes with $4 \mathrm{~mL}$ of typical aqueous solution found where ferrous sulfamate (FS) is added to the process (i.e., stage 4 of D Bank, which has $0.9 \mathrm{M} \mathrm{HNO}_{3}$ and $0.05 \mathrm{M} \mathrm{FS}$ ). The solutions were mixed in a

\footnotetext{
${ }^{4}$ Crowder, M.L, and M.C. Thompson, Ferrous Sulfamate Studies for $2^{\text {nd }}$ Uranium Cycle, WSRC-TR-200200389, in press.
} 
vortex mixer for one minute. Time for disengagement was recorded. After initial testing, ferrous sulfamate (FS) solids were added to both tubes. The results are in Table 3.

Table 3. Disengagement Time (sec) for $7.5 \%$ TBP

\begin{tabular}{|c|c|c|c|}
\hline & $\begin{array}{c}\text { New } \\
\text { Solvent }\end{array}$ & $\begin{array}{c}\text { Tank 902 } \\
\text { Solvent }\end{array}$ & $\begin{array}{c}\text { Alumina-treated } \\
\text { Tank 902 Solvent }\end{array}$ \\
\hline Stage D4 (No solids) & 29,32 & 43,34 & 34 \\
\hline Stage D4 + FS solids & 36 & 59 & NT \\
\hline Stage D4 (aged FS)* & 76 & 96 & NT \\
\hline
\end{tabular}

*Aged FS contributed the most solids; NT = Not Tested

Because disengagement time is a subjective test, each number in the table represents four repetitions. The comparison between new and Tank 902 solvents was statistically significant at the $95 \%$ confidence level for each level of solids. This difference can be attributed to the partial degradation of n-paraffin mentioned earlier. The ratio of disengagement times for the two solvents is always less than two. This compares favorably with plant data from the 1980 's. ${ }^{5}$

The effect of FS solids was examined because ferrous sulfamate oxidizes over time by exposure to air. The resulting ferric ions precipitate with sulfamate-like anions. Currently, the FS solution used in $2^{\text {nd }}$ Uranium Cycle must pass through a 3-micron filter before reaching the process. Analysis of FS solids showed that particle size ranges from 1 to 10 microns, and approximately $45 \%$ of FS solids would pass through a 3-micron filter. Thus, a portion of FS solids could be reaching the mixer-settlers. (Once again, more information on ferrous sulfamate solids is provided separately $\left.{ }^{4}\right)$.

As shown in Table 3, FS solids increased the disengagement time. Even after disengagement, the aqueous layer was very cloudy when FS solids were present. The test with aged FS involved the most solids, and gave the highest increase in disengagement time. With aged FS, the phases never fully disengaged in the last two replications. The time of $90 \%$ disengagement was used. After 5 minutes, the phases were still only $90 \%$ disengaged. Hence, the presence of FS solids, or presumably any solids, would increase disengagement time and increase the level of entrainment in the $2^{\text {nd }} \mathrm{U}$ Cycle.

To reduce variability, the main test for solvent quality was changed in 1987 from disengagement time to interfacial tension. As interfacial tension decreases, disengagement time increases. ${ }^{6,7}$ Based on data ${ }^{8}$ for 2001, the solvent in these tests had an interfacial tension (IFT) in the range of $9.1 \pm 0.4 \mathrm{dynes} / \mathrm{cm}$. This is consistent with data from the 1990's, but about $15 \%$ lower than values observed in the late 1980's. ${ }^{5}$ Compared to the minimum IFT value, 7 dynes/cm, the solvent was in good condition.

\footnotetext{
${ }^{5}$ Dhom, D., personal communication, July 2002.

${ }^{6}$ Reif, D.J., "Solvent Quality Test," DPST-85-877, Oct. 28, 1985.

${ }^{7}$ Mailen, J.C. and O.K. Tallent, "Solvent Cleanup and Degradation: A Survey and Recent ORNL Results," Oak Ridge National Laboratory, Oak Ridge, TN, Contract No. DE-AC05-840R21400.

${ }^{8}$ Foreman, Angela, personal communication, Dec. 2001.
} 
A final test related to solvent quality involved alumina cleaning. Alumina was activated by heating to $180^{\circ} \mathrm{C}$ for six hours, then stored in a dessicator to cool. Later, solvent (7.5\% TBP from Tank 902) was mixed with alumina for 24 hours at a 10:1 solvent to alumina ratio. (It should be noted that for larger volumes the recommended residence time of solvent in an alumina column is on the order of only 4 minutes. ${ }^{9}$ ) Alumina contacting removed some of the light yellow color from Tank 902 solvent. However, no significant improvement in disengagement time was observed. This is not surprising, since the as-received Tank 902 solvent was in very good condition.

\section{Conclusions}

The results of this study led to the following conclusions:

1. The solvent from Tank 902 received in June 2001 was of very good quality and was not a cause of product contamination problems.

2. The presence of ferrous sulfamate solids increased the time required for solvent and aqueous phases to separate.

3. Alumina treatment of the solvent reduced color, but did not significantly improve the disengagement time of as-received solvent.

\section{Acknowledgments}

The authors thank the following for their excellent support:

Mike Lee for laboratory assistance, the Analytical Development Section of the Savannah River Technology Center for a wide range of analyses, Angela Foreman for interfacial tension results, and Dawn Dhom for collecting historical data.

\footnotetext{
${ }^{9}$ Reif, D.J., "F-Canyon First Cycle Solvent”, WSRC-RP-89-210, May 8, 1989.
} 


\section{Distribution:}

D.W. Braselman, 705-H

D. M. Dhom, 704-2H

A.S. Foreman, 772-F

R.A. Frushour, 704-2H

J.H. Gray, 773-A

B.C. Hill, 773-41A

A.T. Johnson, 221-H

E.A. Kyser, 773-A

J.R. Lint, 221-H

R.M. Mobley, 703-F

A.M. Murray, 773-A

C.E. Pickett, 221-13H

B.A. Posnick, 221-H

A.F. Riechman, 773-41A

S.J. Robertson, 707-F

O.L. Rodriquez, 705-H

G.J. Winkler, 704-2H

S.A. Yano, 704-2H 